\title{
Análise sobre modelos atômicos em Livros Didáticos de Química segundo a História e Filosofia da Ciência
}

\author{
Analysis on atomic models in Chemistry Textbooks according to the History and \\ Philosophy of Science \\ Camila Bignardi ${ }^{1}$ \\ UNESP Campus Presidente Prudente \\ Gustavo Bizarria Gibin ${ }^{2}$ \\ UNESP Campus Presidente Prudente
}

\begin{abstract}
RESUMO
Nesse artigo os livros didáticos de Química do Programa Nacional do Livro e do Material Didático (PNLD) 2018 foram analisados em relação ao uso de História e Filosofia da Ciência (HFC) em capítulos sobre modelos atômicos. Foi analisado se o livro didático emprega a HFC, adaptando as propostas de Ternes, Scheid e Gullich (2009) e Vidal e Porto (2017). Foram analisados os seguintes aspectos: as biografias dos cientistas, a descrição e representação dos experimentos, apresentação do aspecto coletivo no desenvolvimento científico, presença de contexto histórico e se foi utilizado o conceito de revoluções científicas de Thomas Kuhn (2013). Foi observado que os livros didáticos apresentam o trabalho dos cientistas como praticamente individual e não é discutido o papel das sociedades científicas no processo de construção da Ciência. O contexto histórico foi pouco empregado para descrever como ocorre o desenvolvimento das teorias científicas. Foi observado que os livros abordaram a HFC de forma muito superficial e o desenvolvimento científico é apresentado apenas como uma construção linear. É importante empregar a HFC de forma mais aprofundada para proporcionar avanços nas concepções dos estudantes sobre a natureza da Ciência.
\end{abstract}

Palavras-chave: Ensino de Química; PNLD 2018; Livros didáticos de Química; História e Filosofia da Ciência.

\begin{abstract}
In this article, the Chemistry textbooks of the Didactic Book National Program of 2018 were analyzed in relation to the use of History and Philosophy of Science (HPS) in chapters on atomic models. It was analyzed whether the textbook employs HPS, adapting the proposals of Ternes, Scheid and Gullich (2009) and Vidal and Porto (2017). The following aspects were analyzed: the scientists' biographies, the description and representation of the experiments, presentation of the collective aspect in scientific development, presence of historical context and whether the concept of scientific revolutions by Thomas Kuhn (2013) was used. It was observed that textbooks present the work of scientists as practically individual and the role of scientific societies in the process of building Science is not discussed. The historical context was little used to describe how the development of scientific theories occurs. It was observed that the books addressed HPS in a very superficial way and scientific development is presented only as a linear construction. It is important to employ HPS in more depth to provide advances in students' conceptions of the nature of science.
\end{abstract}

Keywords: Chemistry teaching; Chemistry textbooks; History and Philosophy of Science.

\footnotetext{
${ }^{1}$ Licenciada em Química pela Faculdade de Ciências e Tecnologia, UNESP, Presidente Prudente, São Paulo, Brasil. Endereço para correspondência: Rua Roberto Simonsen, 305, Centro Educacional, Presidente Prudente, São Paulo, Brasil, CEP: 19060-900. ORCID iD: https://orcid.org/0000-0001-6162-1853 E-mail: g.bignardi@unesp.br.

${ }^{2}$ Doutor em Ciências pelo PPGQ-UFSCar. Professor assistente doutor na UNESP, Presidente Prudente, São Paulo, Brasil. É credenciado no Programa de Pós-Graduação em Ensino e Processos Formativos. Endereço para correspondência: Rua Roberto Simonsen, 305, Centro Educacional, Presidente Prudente, São Paulo, Brasil, CEP: 19060-900. ORCID iD: https://orcid.org/0000-0001-9473-255X E-mail: gustavo.gibin @unesp.br.
} 
Caderno Amazonense de Pesquisa

em Ensino de Ciências e Matemática

\section{INTRODUÇÃO}

O livro didático (LD) é um dos materiais didáticos mais utilizados por professores no Ensino Médio (SANTOS e MARTINS, 2011). Esse material pode nortear os trabalhos dos professores em relação ao currículo e às atividades que podem ser realizadas com os estudantes.

O livro didático consiste no material didático mais empregado em sala de aula, nos diferentes níveis de ensino no país (SANTOS e MARTINS, 2011). Desde o período colonial, no Brasil, os livros didáticos são empregados na educação, dada a sua importância como material didático que permite a apresentação de conteúdos aos discentes (AYIK e COSTU, 2020). A partir de 1937, o Brasil criou um programa de distribuição de livros didáticos para escolas públicas da educação básica, chamado Programa Nacional do Livro Didático (PNLD), desenvolvido pelo Ministério da Educação (MEC). O PNLD sofreu diversas alterações até hoje, e também foi ampliado, de forma que apenas não fornece livros didáticos aos alunos da Educação Infantil. No PNLD, a avaliação é feita pelo MEC, com especialistas da área de conhecimentos específicos, conhecimentos didáticos, do Ensino Superior e da Educação Básica. As obras aprovadas são apresentadas no Guia do Livro Didático do PNLD, para orientar os professores na escolha dos livros didáticos (BRASIL, 2021).

A História e Filosofia da Ciência (HFC) pode ser empregada na construção de livros didáticos com o objetivo de promover melhorias no ensino de Ciências e de Química. A HFC permite uma aproximação entre o conhecimento científico e químico ao conhecimento dos alunos (MATTHEWS, 1994; COLLINS, 2021). Com o emprego da HFC no ensino de Ciências e de Química, é possível discutir as revoluções científicas, de acordo com a visão de Thomas Kuhn (2013), ou seja, como a Ciência foi construída histórica e socialmente e em muitos casos, ocorreram momentos de rompimento violento em relação às teorias científicas aceitas previamente pela sociedade científica (KUHN, 2013).

Entretanto, em muitos casos, os livros didáticos (LD) de Química não empregam ou utilizam muito pouco a HFC como uma abordagem para discutir a natureza da Ciência. A Ciência é geralmente apresentada apenas como um conjunto de conhecimentos que cresce de forma linear e sobre os cientistas, na maioria das vezes, apenas são relatados os seus nomes, datas de nascimento e de morte, além da sua contribuição científica. É importante que os estudantes compreendam como a Ciência é construída e que não apresentem visões deformadas sobre ela. É necessário que o estudante conheça melhor o contexto histórico das teorias científicas, como as sociedades científicas desenvolviam e debatiam as ideias, até se tornar um 
Caderno de Pesquisa em Ensino

de Ciências e Matemática

consenso. Essa compreensão sobre a natureza da Ciência pode envolver mais o aluno e promover avanços na aprendizagem de Química (MATTHEWS, 1994; PATTERSON et al., 2017; COLLINS, 2021).

Dessa forma, nesse trabalho foi escolhida a análise de livros didáticos segundo o prisma da HFC, em específico o olhar de Thomas Kuhn. O tema a ser analisado nos LD é de modelos atômicos, pois os estudantes geralmente possuem dificuldades de compreensão sobre esse conteúdo, visto ser abstrato e referir-se ao mundo atômico, que não é observável diretamente (ROCHA e CAVICCHIOLI, 2005). Para Romanelli (1996), ao ensinar o conceito de átomo, é necessário abordar o conceito de modelo, discutir palavras e símbolos que são diferentes dos conhecimentos cotidianos dos alunos.

\section{FUNDAMENTAÇÃO TEÓRICA}

A Ciência é um tipo de conhecimento confiável, pois é construído de forma objetiva e empírica. Essa é uma visão que foi construída em um período em que as Ciências evoluíram por meio de diversas descobertas, que influenciavam umas às outras, portanto, ocorria um crescimento linear do conhecimento científico (CHALMERS, 1993). Entretanto, hoje sabemos que essa é uma visão bastante ingênua e até mesmo problemática sobre a natureza da Ciência.

A Ciência tem a sua origem na Grécia antiga, por meio da filosofia aristotélica, que originou muitas concepções relevantes até hoje para a natureza da Ciência. A Ciência Normal, segundo Kuhn (2013) é construída por meio de pesquisas fortemente baseadas em uma ou mais investigações científicas passadas. Assim, a Ciência é construída sobre paradigmas, que são um conjunto de conhecimentos científicos aceitos pela comunidade científica, que proporcionam por um tempo problemas e também suas soluções. Além disso, podem ocorrer momentos de ruptura no desenvolvimento da Ciência, quando ocorrem mudanças de paradigma, e dessa forma, são realizadas mudanças profundas na História da Ciência. Kuhn chama essas mudanças de revoluções científicas.

Matthews (1994) defende que ao discutir os aspectos da HFC, o aluno pode compreender melhor como a Ciência é desenvolvida e assim, se aproximar do conhecimento científico. Além disso, essa abordagem no ensino de Ciências e de Química pode auxiliar na desconstrução de concepções deformadas sobre a natureza da Ciência (RIBAS e AIRES, 2012).

Gil-Pérez et al (2001) relatam que na literatura existem várias visões deformadas sobre a natureza da Ciência e o trabalho do cientista. A primeira visão deformada sobre a Ciência é a

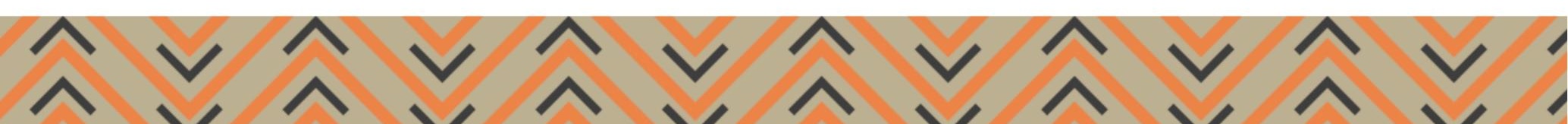


empírico-indutivista e ateórica, na qual é considerado apenas o papel erroneamente atribuído como neutro da observação e da experimentação. Nessa visão, não são consideradas as hipóteses e teorias que orientam todo o processo de desenvolvimento científico. Outra visão deformada é a visão rígida sobre a Ciência, vista como algo exato e infalível, como um único "método científico", em que uma sequência de etapas é seguida de forma rígida. Nessa visão, não são considerados outros aspectos que envolvem a Ciência, como a criatividade e a intuição dos cientistas. A visão aproblemática e ahistórica consiste em uma percepção de que a Ciência é um corpo de conhecimentos fechado, em que não ocorreu uma evolução, não houveram dificuldades em sua construção. Não é levado em conta que a Ciência é inserida em uma sociedade, dentro de um contexto histórico, no qual existem problemas a serem solucionados. Portanto, a Ciência vai ser construída por meio da busca de soluções para problemas de uma sociedade que é fruto de sua época. Outra visão deformada é a exclusivamente analítica, em que são destacados um caráter simplificador, de divisão do trabalho científico em partes de conhecimentos. Assim, é considerado que que cada conhecimento fica isolado e não interage com outros conhecimentos. Na visão acumulativa de crescimento linear, a Ciência é vista apenas como um conjunto de conhecimentos que sempre é ampliado com novas pesquisas. Assim, são desconsideradas as revoluções científicas, em que ocorrem mudanças de paradigma de uma sociedade científica. Outra visão deformada é a individualista e elitista da Ciência, na qual os cientistas são vistos como gênios, que trabalham apenas de forma isolada e são esquecidos vários aspectos do trabalho coletivo, como a dinâmica dos grupos de pesquisa, das interações entre grupos e das sociedades científicas. Por fim, a visão socialmente neutra da Ciência não dá destaque para as relações que existem entre a Ciência, a Tecnologia e a Sociedade. Essas dimensões interferem umas nas outras e certamente influenciam como a Ciência é desenvolvida.

O emprego da abordagem da HFC nos livros didáticos de Química pode proporcionar melhorias nas possíveis visões deformadas sobre a natureza da Ciência apresentadas pelos alunos. Para isso, é importante considerar que essas visões deformadas existem em alunos e professores, e explicar melhor sobre como a Ciência é construída, quais são suas características principais e apresentar exemplos, muitas vezes da História da Ciência ou da História da Química.

A HFC propõe formas de compreender a natureza da Ciência, por meio do estudo de sua história segundo um prisma filosófico. Vários autores apresentam propostas de como a 
Caderno de Pesquisa em Ensino

de Ciências e Matemática

Ciência é desenvolvida e Thomas Kuhn propõe a construção da Ciência, em que as ações sociais dos cientistas são relevantes e que ocorrem Revoluções Científicas. Inicialmente, o autor discute que durante boa parte do tempo, a Ciência Normal é desenvolvida por meio de pesquisas baseadas em conhecimento científico já estabelecido. Esse conjunto de conhecimentos científicos bem definido por uma sociedade científica é chamado de paradigma. $\mathrm{O}$ autor define os paradigmas como "as realizações científicas universalmente reconhecidas que, durante algum tempo, fornecem problemas e soluções modelares para uma comunidade de praticantes de uma ciência" (KUHN, 2013). A Ciência Normal pode ser análoga à resolução de "quebracabeças" (puzzles no original), pois as regras são relativamente bem definidas. Entretanto, na Ciência, os quebra-cabeças são definidos pela natureza. Quando surgem anomalias, ou seja, fenômenos apresentam dados que as teorias vigentes não conseguem explicar, o paradigma pode ficar em risco e entrar em crise. Em seguida, ocorre uma ruptura, com a busca por um novo paradigma. Assim, a ciência normal deixa de ser realizada, pois ela depende de um paradigma aceito por uma comunidade científica. Um novo paradigma passa a ser desenvolvido e quando ele é aceito, passa a entrar em um novo período de Ciência Normal. A mudança de paradigma por uma comunidade científica é chamada de Revolução Científica por Kuhn (2013).

O desenvolvimento de novos paradigmas proporciona uma mudança de visão do mundo. Por exemplo, a teoria do flogisto explicava diversos tipos de reações químicas, como a formação de ácidos a partir da combustão de carbono e enxofre. Entretanto, com o desenvolvimento da teoria sobre ácidos e bases de Arrhenius, Bronsted-Lowry e Lewis, além da teoria da combustão de Lavoisier, o paradigma do flogisto foi abandonado. Esse tipo de mudança de paradigma ocorre nas revoluções científicas. Portanto, as ideias de Kuhn (2013), em especial sobre as revoluções científicas podem ser discutidas com estudantes de Ensino Médio, para auxiliar no desenvolvimento de uma melhor concepção sobre a natureza da Ciência.

Neste artigo, o objetivo foi avaliar a forma em que a História e Filosofia da Ciência é abordada nos livros didáticos de Química do Ensino Médio, sobre o conteúdo de modelos atômicos. Outro objetivo foi analisar se a HFC abordada nos LD é coerente com as ideias de Thomas Kuhn, ou seja, se são apresentadas as revoluções científicas e o processo social durante a construção da Ciência, ou se a Ciência é apresentada apenas de forma que seu crescimento é realizado de forma linear.

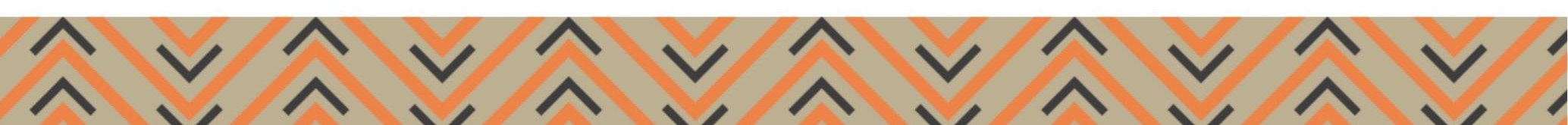




\section{METODOLOGIA}

Foram analisados os capítulos que abordam o tema de modelo atômico nos seis livros didáticos de Química aprovados pelo PNLD 2018. Foi realizada uma análise nas obras em relação à abordagem de certos aspectos da HFC nesse tema. As categorias de análise foram adaptadas dos trabalhos de Ternes, Scheid e Gullich (2009) e Vidal e Porto (2012), em que os livros didáticos de Ciências do Ensino Fundamental e LD de Química aprovados pelo PNLD foram analisados em relação ao uso do HFC, respectivamente.

A análise contou com seis categorias, apresentadas a seguir:

1) Biografia do cientista;

2) Descrição dos experimentos;

3) Representação de experimentos;

4) Apresentação ou não do aspecto coletivo da construção das Ciências;

5) Presença do contexto histórico;

6) Evolução linear do crescimento linear do conhecimento científico ou são apresentadas revoluções científicas.

Na primeira categoria, são analisadas como são abordadas as biologias dos cientistas, se são apresentadas apenas as datas de nascimento e de morte dos cientistas, contribuições, histórias curiosas. Também são analisados se foram apresentadas características pessoais, histórias de vida e atuações relevantes em sua sociedade. Nas categorias 2 e 3, sobre os experimentos desenvolvidos, foram analisados a descrição da sua realização e as formas de representações utilizadas. Na quarta categoria, foi analisado se a Ciência é apresentada como uma atividade individual realizada pelos cientistas ou envolve aspectos coletivos. Na quinta categoria, foi analisado se existe uma discussão sobre o contexto histórico e é estabelecida uma relação com as atividades científicas. E na última categoria foi analisado como é descrita a construção da Ciência, se a mesma é desenvolvida apenas por meio do crescimento linear de seus conhecimentos ou se ocorrem as revoluções científicas, segundo Kuhn. Em um crescimento linear, é mostrado apenas que cada conceito evolui para outro mais específico ou mais adequado, já em uma revolução científica, é realizada uma grande discussão na sociedade científica e é feita uma mudança brusca de paradigma, ou seja, ocorre uma substituição de um corpo de conhecimentos estabelecido por outro.

Os livros didáticos que foram analisados são apresentados no quadro 1. Também estão 
Caderno de Pesquisa em Ensino de Ciências e Matemática

apontados os capítulos sobre modelos atômicos que foram selecionados para análise.

Quadro 1 - Relação de livros didáticos analisados.

\begin{tabular}{|c|c|c|c|c|}
\hline Livro & Título & Autores & Volume & Capítulos \\
\hline 1 & Química & Ciscato, et al. & 1 & 3 \\
\hline 2 & Vivá & Novais e Antunes & 1 & 2 e 4 \\
\hline 3 & Ser Protagonista - Química & Lisboa, et al. & 1 & 5 \\
\hline 4 & Química & Martha Reis Fonseca & 1 & 4 e 6 \\
\hline 5 & Química & Mortimer e Machado & 1 & 6 \\
\hline 6 & Química Cidadã & Santos e Mól (orgs) & 1 & 5 \\
\hline
\end{tabular}

Fonte: Elaboração pelos autores.

Em cada livro didático, foram selecionados os capítulos que tratam sobre modelos atômicos e inicialmente foram marcados e recortados todos os trechos e figuras dos textos, que abordaram os aspectos históricos de interesse da pesquisa. Esses recortes foram categorizados de acordo com as categorias propostas previamente, de acordo com os trabalhos da literatura. A seguir, são apresentados os principais resultados e os destaques são detalhados nos exemplos.

\section{RESULTADOS E DISCUSSÃO}

Os livros didáticos apresentados no quadro 1 foram analisados segundo as categorias adaptadas dos trabalhos de Ternes, Scheid e Gullich (2009) e Vidal e Porto (2012). No quadro 2 é apresentada uma síntese dos resultados obtidos na análise dos dados coletados nos LD.

Quadro 2 - Síntese da análise de dados realizada nos livros didáticos.

\begin{tabular}{|c|c|c|c|c|c|c|}
\hline \multirow{2}{*}{ LD } & \multicolumn{7}{|c|}{ Categorias de análise } \\
\cline { 2 - 7 } & Biografias & $\begin{array}{c}\text { Descrição dos } \\
\text { experimentos }\end{array}$ & $\begin{array}{c}\text { Representação } \\
\text { de experimentos }\end{array}$ & $\begin{array}{c}\text { Aspecto coletivo } \\
\text { da Ciência }\end{array}$ & $\begin{array}{c}\text { Contexto } \\
\text { histórico }\end{array}$ & $\begin{array}{c}\text { Revoluçães } \\
\text { científicas }\end{array}$ \\
\hline 1 & Sim & Sim & Sim & Individual & Não & Não \\
\hline 2 & Sim & Sim & Sim & Individual & Não & Não \\
\hline 3 & Sim & Sim & Sim & Individual & Não & Não \\
\hline 4 & Sim & Sim & Sim & Individual & Não & Não \\
\hline 5 & Sim & Sim & Sim & Individual & Sim & Não \\
\hline 6 & Sim & Sim & Não & Individual & Não & Não \\
\hline
\end{tabular}

Fonte: Elaboração pelos autores.

De forma geral, conforme o quadro 2, os aspectos da História de Filosofia da Ciência são trabalhados nos livros didáticos, entretanto, na maior parte das vezes é feito de forma muito superficial. As biografias dos cientistas são brevemente apresentadas e na maioria das vezes, são relatados apenas a data de seu nascimento, a data da contribuição científica e de sua morte. Em todos os livros didáticos são apresentados os experimentos científicos relevantes do ponto de vista histórico. Esses experimentos são apresentados nos livros por meio de textos e de 
imagens. Em todos os textos didáticos também são apresentadas apenas as contribuições individuais dos cientistas, sem discussões sobre o aspecto coletivo da construção do conhecimento científico. Apenas uma obra didática apresentou de forma rápida um contexto histórico, que é relevante para compreender o trabalho dos cientistas. Outro ponto relevante é que nenhuma obra abordou a ocorrência de revoluções científicas. Em todos os LD a construção do conhecimento científico é mostrada de forma unicamente linear.

A seguir, os principais dados de cada categoria são apresentados e discutidos com mais detalhes.

\section{Biografias dos cientistas}

Foi observado que na maioria dos livros, as biografias produzidas nos textos são altamente superficiais, com geralmente apenas o ano de nascimento e de morte dos cientistas, sendo apresentadas apenas quando fazem referência à alguma Lei ou descoberta científica (PANTANO et al., 2021). Isso não permite ao leitor o estabelecimento de uma relação com o personagem abordado no livro. Assim, não é dada uma dimensão humana aos cientistas, praticamente não foram apresentadas as suas histórias, e dessa forma, torna difícil a superação de concepções deformadas sobre a Ciência e o cientista, como a de que os cientistas são gênios, que vivem e trabalham de forma isolada (CACHAPUZ, et al., 2005).

No LD2, a apresentação altamente concisa da biografia de Priestley é a seguinte: “[...] atribuem essa descoberta a Joseph Priestley (1733-1804), que, em 1774, divulgou a descoberta de um gás que alimentava melhor a combustão do que o ar. [...]” (LD2, p. 86).

Nessa mesma obra, existem algumas biografias um pouco mais detalhadas, apresentadas em caixas de texto. São destacadas as realizações dos cientistas, como os prêmios recebidos, por exemplo, na figura 1 é apresentada uma rápida biografia de Marie e Pierre Curie.

Figura 1 - Caixa de texto com a biografia de Marie e Pierre Curie (LD2). 


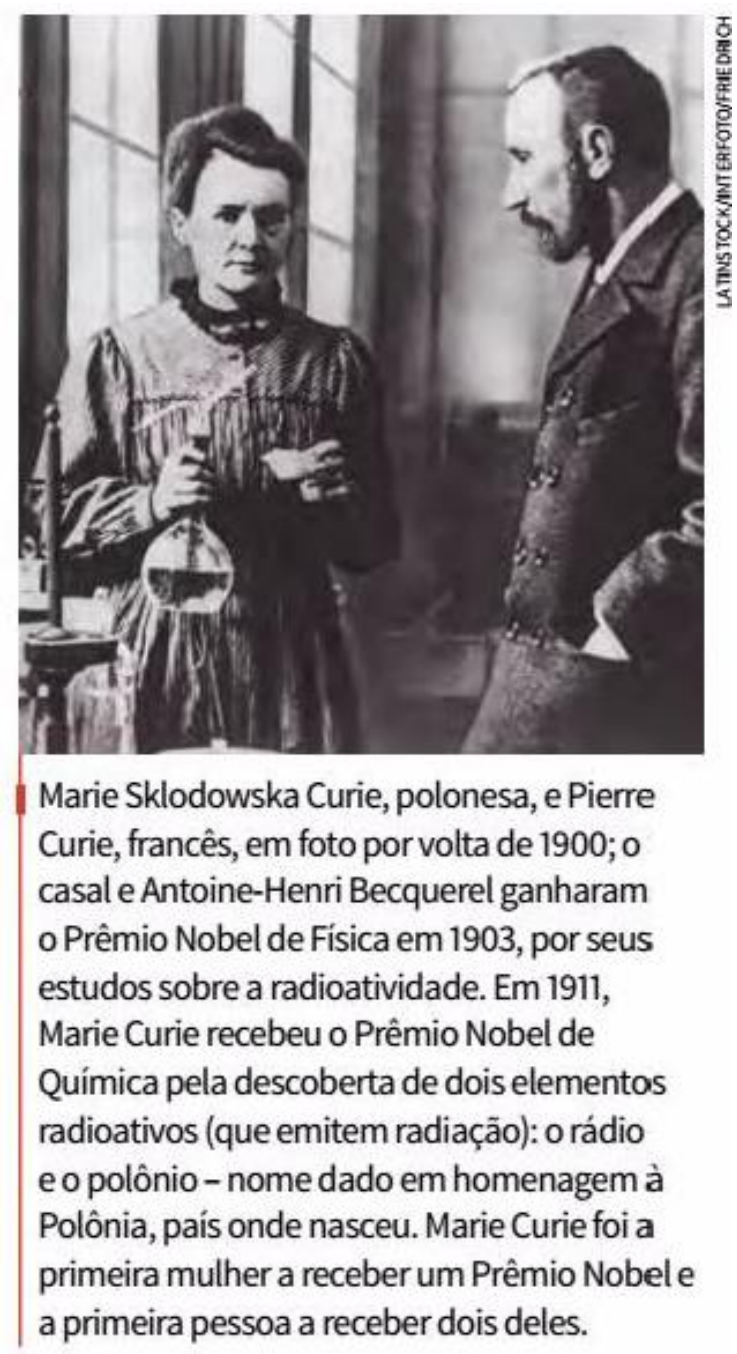

Fonte: Novais e Antunes (2016).

Nesse exemplo, apesar de sucinta, essa caixa de texto apresenta mais informações do que os outros textos didáticos. É interessante ampliar as informações apresentadas sobre a história de cientistas, porém, a utilização de caixas de texto pode induzir o leitor a entender que essas informações não são tão relevantes, pois não constam do corpo do texto principal. Assim, as caixas de texto podem não ser empregadas por professores em suas aulas e nas leituras pelos estudantes.

No LD3 também é feita uma apresentação sintética das biografias dos cientistas, como as datas de nascimento, morte e qual foi a sua principal contribuição científica. No seguinte exemplo é apresentada a biografia de Dalton: “[...], quando John Dalton (1766-1844) elaborou um modelo de estrutura da matéria que explicava os fenômenos químicos já identificados, o conceito de átomo já era conhecido" (LD3, p. 77). Nos LDs 4 e 5 são feitas apenas as indicações das datas de nascimento e morte dos cientistas. Cabe salientar que citar apenas a data de

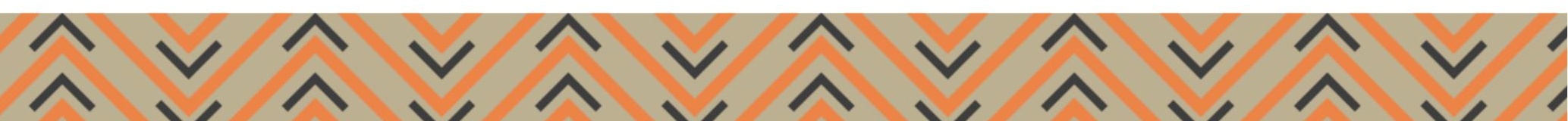


nascimento e de morte dos cientistas não permite compreender sobre a História da Química e da Ciência.

O LD6 aponta as principais contribuições de cada cientista, além do ano de nascimento e de morte, conforme os seguintes exemplos.

[...] Dalton desenvolveu sua teoria inspirando-se nas ideias atomistas do físico inglês Isaac Newton [1642-1727], tomando como referência os estudos meteorológicos e pesquisas sobre a solubilidade dos gases em água que Dalton vinha desenvolvendo [...] (LD6, p. 150).

[...] físico japonês Hantaro Nagaoka [1865-1950] apresentou à Sociedade de Física e Matemática de Tóquio um artigo sobre o movimento de partículas num átomo ideal. Nele, propôs seu modelo saturniano de átomo. [...] (LD6, p. 154).

Além desses exemplos, consta no texto uma caixa, chamada História da Ciência, que aborda a biografia e os destaques científicos de Ernest Rutherford. Essa caixa de texto é apresentada na figura 2 .

Figura 2 - Caixa de texto de título História da Ciência com a biografia de Rutherford (LD6).

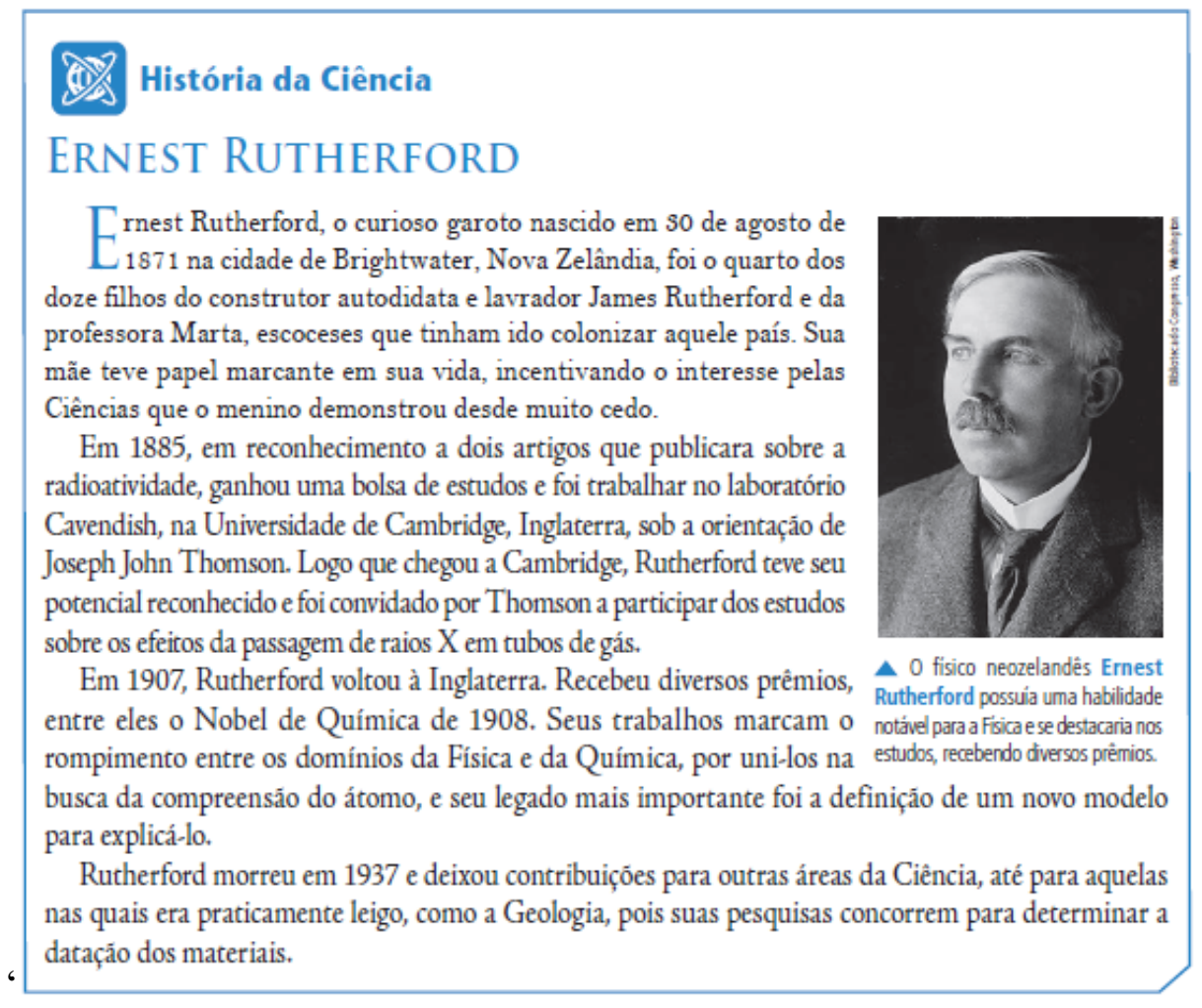

Fonte: Santos e Mól (2016).

A informação apresentada na figura 2 é mais completa do que a observada nos demais textos didáticos, pois são abordados a vida e a obra de cientistas historicamente importantes, o 
Caderno de Pesquisa em Ensino

de Ciências e Matemática

que é importante para promover avanços na compreensão sobre a natureza da Ciência. Também são apresentadas características pessoais do cientista, como um garoto curioso e também algumas características de sua família.

Entretanto, a estratégia de utilizar caixas para apresentar a História da Química pode ser falha, no sentido de que os leitores, tanto alunos quanto professores, podem entender que esse segmento é opcional, não tão importante, uma curiosidade, e pode ser deixado de lado ao ler o texto principal. É importante que as informações históricas estejam no corpo do texto principal, pois abordam conteúdos importantes para a compreensão da Química e sobre a sua natureza.

Em suma, na maioria dos livros didáticos, a biografia dos cientistas foi abordada de forma excessivamente superficial, geralmente apenas com uma rápida discussão sobre a principal contribuição científica, além das datas de nascimento e morte. Houve o emprego de caixas de texto, com dados mais detalhados sobre a obra dos cientistas, porém, constam fora do corpo do texto principal, o que pode proporcionar ao leitor a ideia de que consiste em um conteúdo de leitura opcional.

Ternes, Scheid e Gullich (2009) obtiveram dados semelhantes e os autores defendem que a História da Ciência não pode ser reduzida a apenas algumas informações biográficas dos cientistas, pois isso não auxilia na compreensão de como ocorre o desenvolvimento científico.

\section{Descrições dos experimentos e observações realizadas pelos cientistas}

Em geral, nos LD foram feitas descrições sintéticas sobre os experimentos, observações e conclusões realizadas pelos cientistas. Em algumas obras, também foram utilizados imagens e quadros para explicar esses experimentos.

No livro 1, é feita uma discussão sobre os experimentos realizados e as explicações dadas pelos cientistas de forma bastante sintética. A seguir é apresentada uma explicação sobre os experimentos que envolvem as massas atômicas:

[...] Os átomos dos elementos químicos oxigênio e hidrogênio se diferenciavam principalmente por suas massas, as quais se mantinham constantes, independentemente das substâncias de que participavam. Para estimar a massa atômica dos diferentes átomos, Dalton combinou os elementos químicos cuja massa desejava determinar com um elemento químico de referência, o hidrogênio, cuja massa classificou como padrão e igual a um. Dessa forma, se a massa atribuída a um determinado elemento químico fosse cinco, isso significa que o átomo desse elemento químico tem massa igual a cinco vezes a massa do átomo de hidrogênio [...] (LD1, p. $85)$. 
No LD2, são descritas de forma sucinta as atividades experimentais e os resultados observados por Rutherford:

[...] Rutherford propôs em 1903 um experimento para determinar a característica dessas emissões radioativas. Ele inseriu uma amostra de material radioativo (polônio) na cavidade de um bloco de chumbo; nesse bloco havia uma pequena abertura para que as radiações emitidas saíssem em uma só direção, impedindo que elas se dispersassem. Um feixe dessas radiações passava entre duas placas de um condensador - uma com carga positiva e outra com carga negativa - e colidia com um anteparo fluorescente. [...] (LD2, p. 48).

No LD4 é feita uma apresentação do experimento de forma um pouco diferente. Apesar da breve abordagem do experimento, é mostrado um quadro com uma representação do sistema experimental, uma descrição dos resultados observados e das conclusões obtidas. Essa apresentação é interessante, pois permite que o professor discuta sobre a natureza da ciência e sobre o papel da experimentação na construção de um conhecimento científico.

Figura 3 - Representação do experimento de Thomson (LD4).

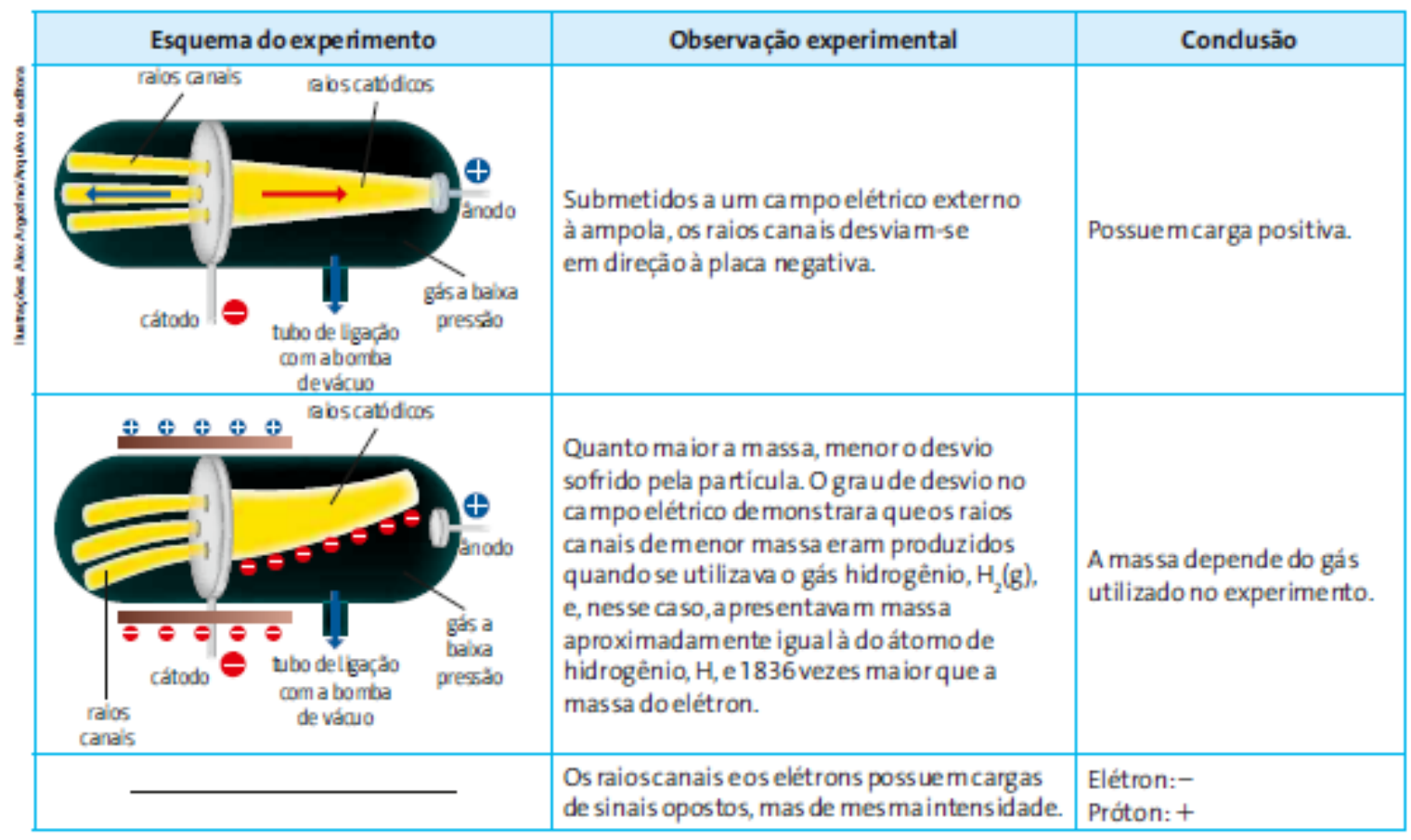

Fonte: Fonseca (2016).

No LD6, o desenvolvimento do modelo de Thomson foi explicado da seguinte forma:

[...] Um desses modelos foi proposto pelo físico inglês Joseph John Thomson [18561940]. Tomando como base as investigações de Faraday, ele realizou experimentos 
com tubos de descarga contendo quatro diferentes gases e utilizou três metais diferentes na constituição dos eletrodos. Os dados coletados nessas experiências permitiram a Thomson alcançar sempre os mesmos valores para a razão entre a carga e a massa do elétron $(\mathrm{e} / \mathrm{m})$, que compunham os raios catódicos, cujos valores eram da mesma ordem de grandeza dos encontrados por Zeeman e Lorentz. Thomson observou, assim, que os raios catódicos eram os mesmos, independentemente, da composição do cátodo, do anticátodo ou do gás na válvula. [...]” (LD6, p. 169).

Não é discutido de forma clara como os conceitos relacionados com o modelo de Thomson foram construídos, mas são apresentados elementos interessantes, como relações entre teoria e práticas experimentais, além de relações com os trabalhos realizados, como os estudos de Faraday foram empregados como uma base teórica e também foram estabelecidas relações dos dados obtidos por Thomson com os de Zeeman e Lorentz. Esses pontos esclarecem um pouco mais como funciona a construção do conhecimento científico, em função da relação entre teoria e prática e também sobre o aspecto social da Ciência, pois ela não é construída pelos cientistas de forma individual, o aspecto coletivo é relevante.

Em geral, sobre esse aspecto, foi observado nos livros didáticos que a descrição dos experimentos é realizada de forma superficial, e que em alguns casos é feita por meio de imagens. Assim, é necessário promover avanços em relação à descrição dos experimentos e as explicações dadas pelos cientistas.

\section{Representações dos experimentos}

No LD1, os experimentos são representados em sua maioria por meio de imagens, como a representação do experimento de Rutherford (figura 4) pode gerar alguma dúvida no leitor, pois é mostrado o sistema de um ponto de vista superior ou elevado. O sistema apresenta apenas o que é observável e não aborda o nível atômico-molecular. É importante discutir a perspectiva utilizada para representar o sistema experimental, para evitar dificuldades de compreensão dos leitores. Cabe salientar que a figura representa o experimento de forma adequada, os elementos abordados permitem compreender o experimento de Rutherford.

Figura 4 - Representação do experimento de Rutherford (LD1). 


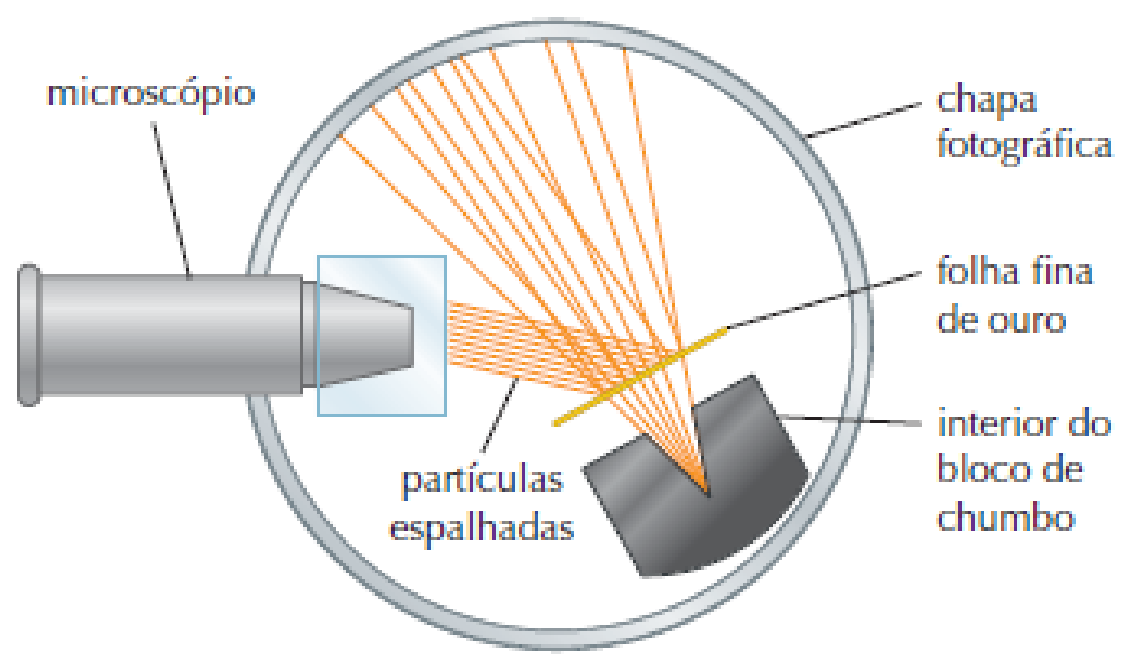

Fonte: Ciscato, et al. (2016).

No LD2, é feita uma representação do experimento de Rutherford, de um ponto de vista lateral, em que são apresentados também todos os elementos necessários para a compreensão do experimento. Como foi feito no livro 1, são apresentados apenas os aspectos observáveis e não são apresentados os átomos de acordo com o modelo de Rutherford (Figura 5).

Figura 5 - Representação do experimento Rutherford (LD2).

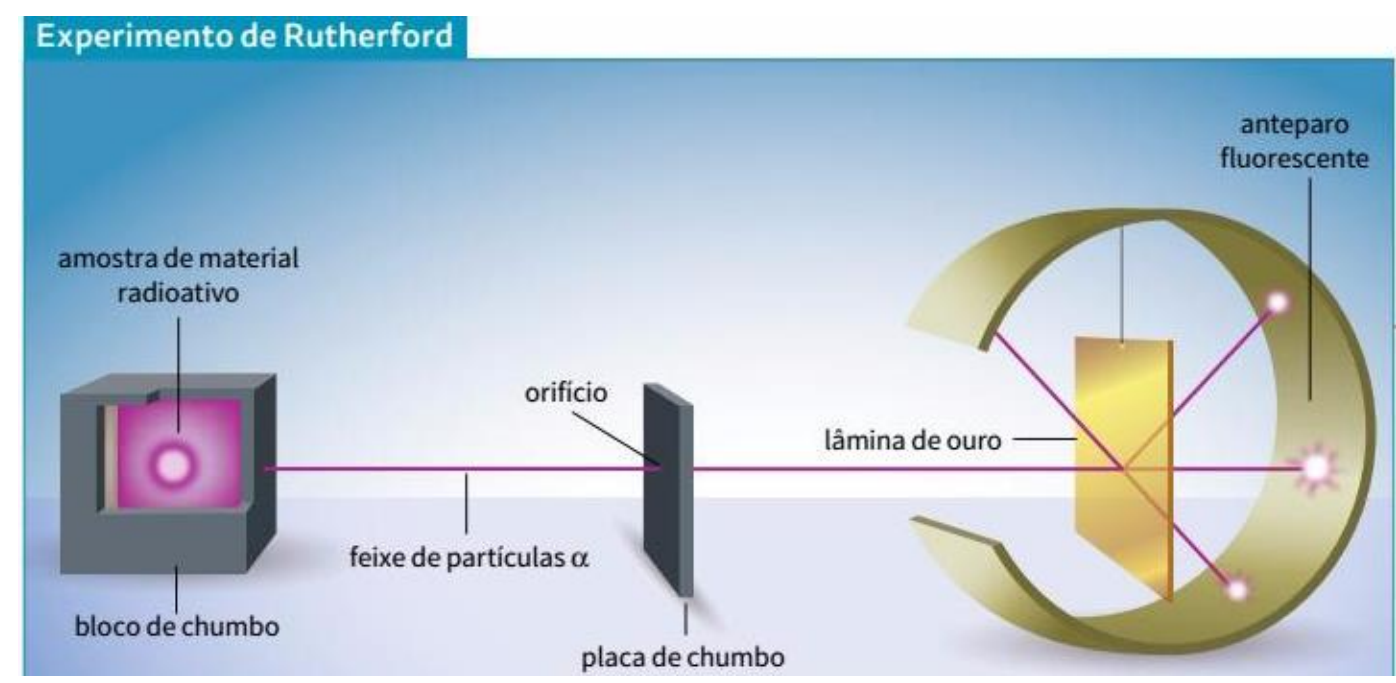

Fonte: Novais e Antunes (2016).

No LD4, também se observou representações de todos os experimentos e modelos atômicos por meio de imagens. A figura 6, apresentada a seguir, representa o experimento de Rutherford.

Figura 6 - Representação do experimento de Rutherford (LD4). 


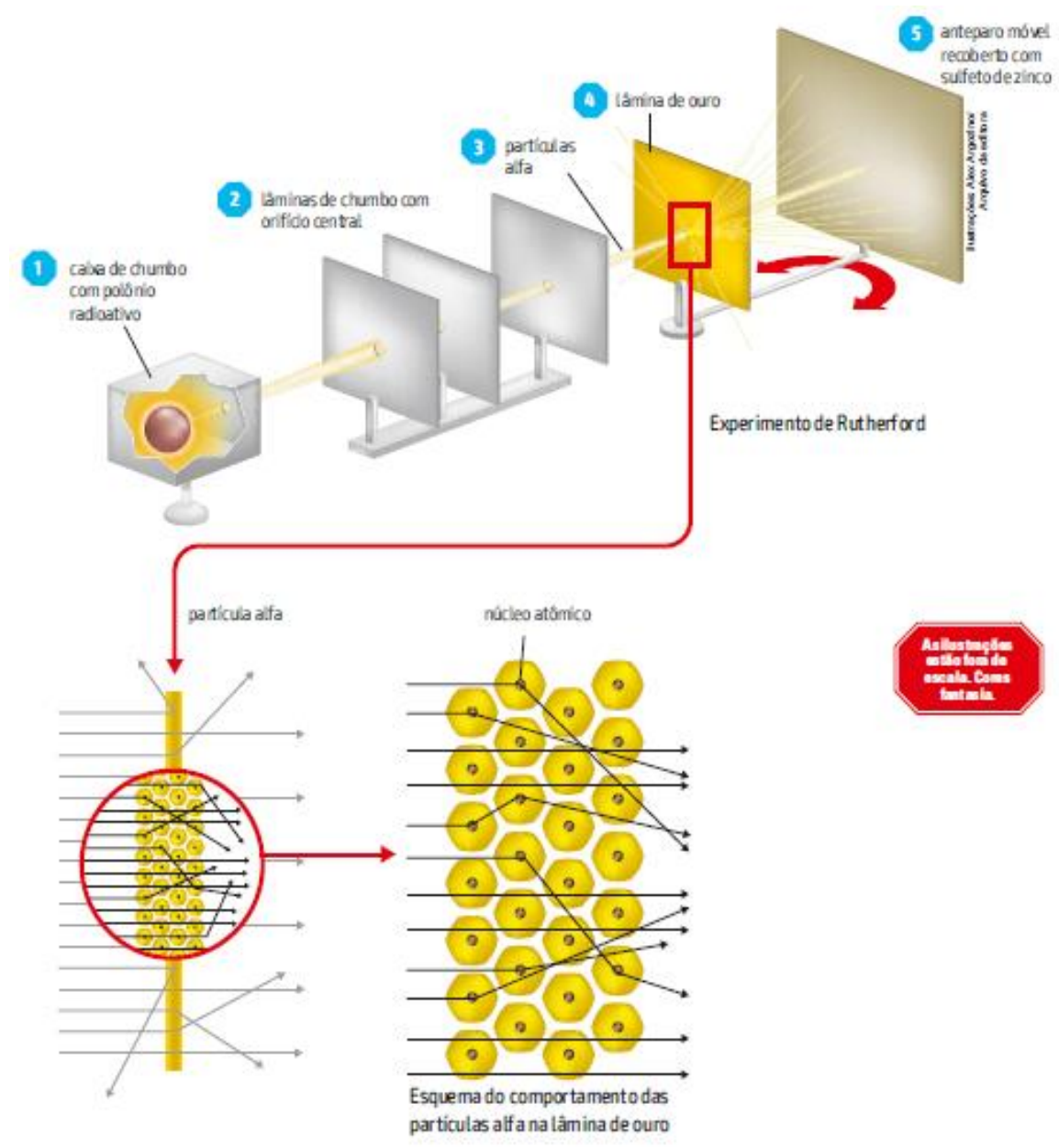

Fonte: Fonseca (2016).

É importante destacar que na figura 6, os autores estabelecem uma relação entre o sistema experimental observável e o modelo atômico de Rutherford com a representação da folha de ouro em nível atômico. O estabelecimento dessa relação pode proporcionar avanços na compreensão dos alunos sobre o experimento e o modelo de Rutherford.

No LD5, há apenas uma representação de experimento no capítulo analisado: o experimento de Rutherford. Como no livro 4, também foi estabelecida uma relação entre o sistema experimental observável e com destaque para a folha de ouro representada em nível atômico. A representação também engloba os elementos do sistema que permitem a compreensão do experimento. É feita uma ampliação da representação do desvio das partículas $\alpha$ em relação ao núcleo dos átomos, que é importante para a compreensão do experimento e sobre o modelo atômico de Rutherford.

Figura 7 - Representação do experimento de Rutherford (LD5). 


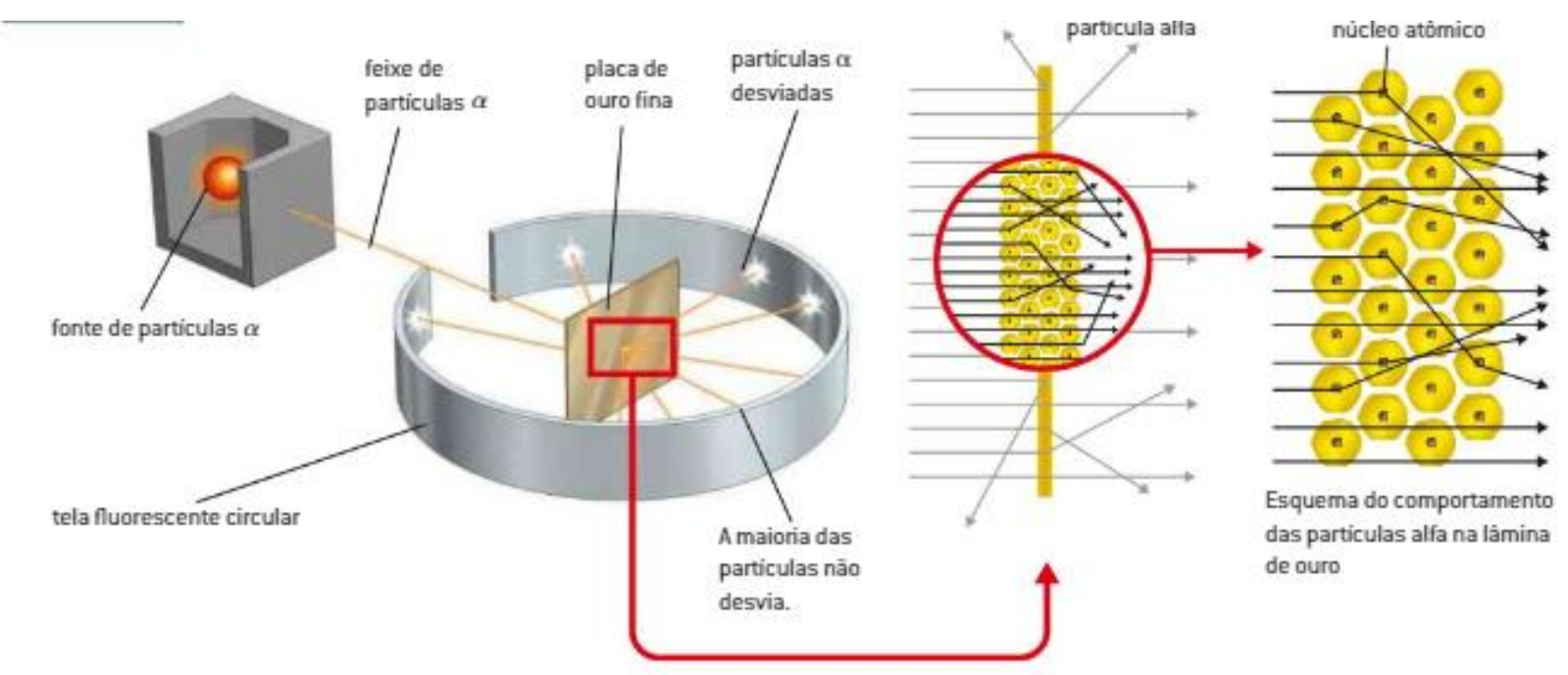

Fonte: Mortimer e Machado (2016).

No livro 6, não há representações sobre os experimentos utilizados no desenvolvimento dos modelos atômicos. Os autores apresentaram representações dos modelos de Dalton e de Thomson. Na Figura 8, são representados os modelos de Dalton de alguns elementos químicos e uma analogia do modelo de Thomson com um panetone. Os elementos semelhantes que permitem a analogia são as passas espalhadas na massa do panetone e os elétrons incrustados em todo o volume do átomo de Thomson.

Figura 8 - Modelos atômicos de Dalton de diferentes elementos químicos e analogia do panetone em relação do modelo atômico de Thomson (LD6).
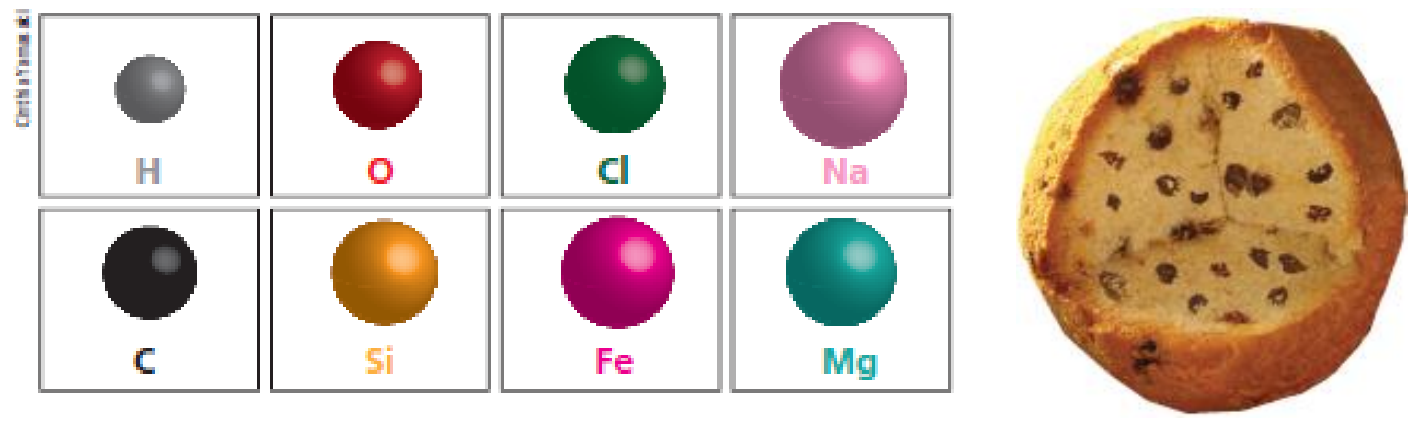

Fonte: Santos e Mól (2016).

Na figura 9 é apresentado o sistema experimental para a construção do modelo de Thomson. Cabe salientar que a representação é muito simplificada e que não há uma legenda ou mesmo texto na própria figura que auxilie na compreensão do sistema. São apresentados apenas os sinais de positivo e negativo em certos locais no sistema, para ajudar a compreender o desvio dos feixes eletrônicos, em termos de repulsão e de atração. Mesmo assim, é necessário 
Caderno de Pesquisa em Ensino de Ciências e Matemática

inserir algum tipo de texto explicativo para elucidar esse experimento.

Figura 9 - Representação do experimento de Thomson (LD6).

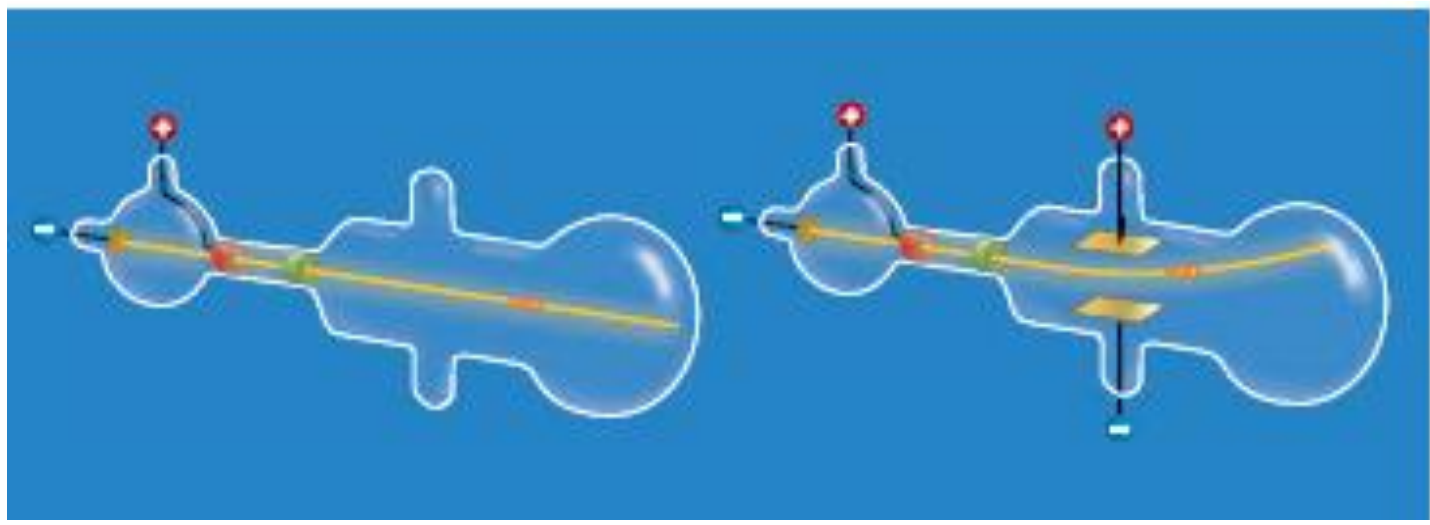

Fonte: Santos e Mól (2016).

Foi observado na maioria dos LD as representações dos principais experimentos que foram feitos para o desenvolvimento dos modelos atômicos. Entretanto, são apresentados de forma muito superficial e há alguns que tentam relacionar o experimento com aspectos importantes da construção do conhecimento científico, como a relação entre teoria e prática, o estabelecimento de relações com dados de outros pesquisadores, mas também esses pontos são abordados de forma muito sucinta. É necessário discutir a importância da experimentação para a construção da Ciência.

Hottecke (2000) relata que nos currículos, existe uma falta de discussão sobre aspectos históricos, filosóficos e sociais relacionados à Ciência, e em específico sobre os experimentos históricos relevantes no Ensino de Ciências. $\mathrm{O}$ autor aponta também que essa discussão também é importante para superar visões deformadas, como a de que um experimento é usado para comprovar teorias científicas e permitir uma compreensão mais adequada sobre o desenvolvimento da Ciência.

\section{A atuação individual dos cientistas e o aspecto coletivo na Ciência}

Em geral, as atividades científicas são descritas como um trabalho individual. Nos livros didáticos não foram trabalhados os aspectos coletivos da Ciência, por exemplo, não foram abordadas as sociedades científicas, eventos científicos e também os grupos de pesquisa, que possuem papeis muito importantes para o desenvolvimento da Ciência. A falta de uma discussão sobre o aspecto coletivo da Ciência pode proporcionar a visão deformada de que os cientistas trabalham unicamente de forma solitária. 
Foi observado no livro 1 que os cientistas são citados de forma individual ou em duplas, como aluno e orientador, conforme os seguintes exemplos:

[...] filósofos como Leucipo de Mileto (cerca de 624 a.C.- -cerca de 546 a.C.) especulavam sobre a composição da matéria, com questões como: de que são feitos o oceano, a areia, a terra o ouro, enfim, toda a matéria que nos rodeia? [...] (LD1, p. 82).

[...] o físico e químico inglês Henry Gwyn Jeffreye Moseley (1887-1915), que foi assistente de Rutherford, propôs que a propriedade que identificava um átomo de um determinado elemento químico não era sua massa, conforme o proposto desde a teoria de Dalton, mas sim o número de prótons do seu núcleo [...] (LD1, p. 85).

[...] Em uma série de experimentos realizados entre 1908 e 1909, o físico Robert Millikan (1868-1953) e seu aluno de doutorado Harvey Fletcher (1884-1981), ambos estadunidenses [...] (LD1, p. 86).

Essa relação entre orientador e orientando é importante, pois é fundamental na formação dos cientistas. Atualmente na universidade, os especialistas formados atuam orientando os pesquisadores nas diversas fases, como na iniciação científica durante a graduação e no mestrado e doutorado durante a pós-graduação. Portanto, é importante explicar de forma mais aprofundada para os alunos do Ensino Médio como essas relações se dão e a importância delas para o desenvolvimento da Ciência.

No LD2, as atividades dos cientistas são apontadas como individuais ou realizadas em pequenos grupos, com relações entre aluno e orientador, como Michael Faraday e Humphry Davy ou as colaborações entre Marie e Pierre Curie e Antoine Becquerel. A seguir são apresentados os exemplos observados no LD2.

[...] Humphry Davy e pelo discípulo deste, Michael Faraday (1791-1867, na primeira metade do século XIX, esse processo - a eletrólise - levou à ideia de que os átomos estariam de alguma forma associados a cargas elétricas [...] (LD2, p. 85).

[...] Um desses estudiosos foi o físico inglês William Crookes. Ele realizou experimentos usando descargas elétricas em gases a baixíssima pressão [...] (LD2, p. 86).

[...] Marie Sklodowska Curie, polonesa, e Pierre Curie, francês, em foto por volta de 1900; o casal e Antoine-Henri Becquerel ganharam o Nobel de Física em 1903, por seus estudos sobre a radioatividade [...] (LD2, p. 88).

No LD3, praticamente todas as atividades científicas são apontadas como realizações individuais, conforme o exemplo a seguir: “[...] nesse contexto, foram muito importantes as contribuições de Jons Jacob Berzellius (1778-1848), que elaborou entre diversos outros trabalhos [...]. (LD3, p. 79). 
Caderno de Pesquisa em Ensino

de Ciências e Matemática

Nos LD5 e LD6, em geral, é relatado que os cientistas praticamente trabalham de forma individual. Também há alguns poucos exemplos que apresentam a ideia de que os cientistas atuam em grupos.

Vidal e Porto (2012) observaram também resultados semelhantes, com uma ampla incidência da concepção de que a Ciência é construída por cientistas, filósofos ou pensadores individuais. Assim, o aspecto coletivo precisa ser abordado de forma mais sistemática e ampla nas discussões que envolvem episódios históricos da Química.

\section{Presença do contexto histórico}

Em geral, nos livros didáticos não existiu uma preocupação em apresentar um contexto histórico como base para o desenvolvimento dos conhecimentos científicos sobre os modelos atômicos. É importante inserir o contexto histórico, bem como as necessidades específicas da sociedade, pois a Ciência busca a solução para problemas que uma sociedade de um período possui.

Foi observada uma discussão sobre o contexto histórico e sobre as tecnologias que existiam nesse período apenas no LD5. Apresentamos a seguir dois recortes desse livro texto a seguir:

[...] Marie Curie, nome que passou a adotar depois de desposar o físico francês Pierre Curie, era polonesa, de nome de solteira Maria Sklodowska. Na impossibilidade de frequentar a Universidade de Varsóvia, por ser mulher, ela mudou-se para Paris em 1891, onde começou a estudar Ciências Físicas na Universidade de Sorbonne. Ela licenciou-se em 1893 em Ciências Físicas e um ano mais tarde em Matemática. (LD5, p. 161).

[...] A ciência do século XX tornou a realidade atômica observável. Várias tecnologias foram desenvolvidas para possibilitar essa observação. Métodos como a difração de raios X permitem determinar a posição e a distância entre as partículas num arranjo cristalino. Apenas na década de 1980 foi desenvolvida uma tecnologia que permite "ver" os átomos de um material. A microscopia de tunelamento fornece imagens de átomos isolados e planos inteiros de átomos na superfície de um material. [...] (LD5, p. 153).

No primeiro excerto é apresentada uma pequena biografia da Marie Curie. É interessante notar que é discutido rapidamente que ela não pôde ter uma educação superior formal e frequentar a Universidade de Varsóvia simplesmente por ser mulher, fato que ainda hoje é atual em diversas localidades do mundo. Esse recorte breve no texto é importante, para se discutir com estudantes do Ensino Médio sobre as imposições sociais às mulheres mesmo no meio acadêmico, pois a Universidade é parte da sociedade e reflete concepções e práticas aceitas 
socialmente. Isso revela um machismo existente na academia nos séculos XIX e XX, que dificultou muito os estudos e a carreira de Marie Curie. Esse é um aspecto importante a ser abordado no Ensino Médio na atualidade.

De forma geral, o contexto histórico não é abordado nos livros didáticos de Química. Essa contextualização é coerente com as orientações da Base Nacional Comum Curricular Ensino Médio (BRASIL, 2017). A contextualização histórica permite conhecer como a ciência é desenvolvida ao longo do tempo, pois a Ciência é construída por pessoas, que estão inseridas na sociedade.

Ternes, Scheid e Gullich (2009) apontam que uma discussão muito simplificada sobre a História da Ciência não permite uma boa compreensão sobre os aspectos sociais, culturais, econômicos que são relacionados com o desenvolvimento científico.

\section{Crescimento estritamente linear do conhecimento científico e revoluções científicas}

Nos livros didáticos analisados, o conhecimento químico sobre atomística é apresentado como uma construção estritamente linear, desde os filósofos gregos antigos até o modelo de Bohr. Assim, parece que houve apenas momentos em que os modelos sofreram evoluções ao longo do tempo, que não houve muita discussão entre os cientistas e trabalho coletivo.

Nenhum dos livros didáticos analisados apresentou algum episódio de revoluções científicas. A discussão sobre as revoluções científicas é importante para o Ensino de Química, pois permite que os estudantes compreendam melhor sobre a natureza da Ciência e como o conhecimento científico é construído.

Santos et al. (2020) apontam que em livros didáticos de Ciências para o Ensino Fundamental não são discutidos os aspectos históricos da Ciência e que as revoluções científicas também não são apresentadas. Essa discussão pode proporcionar avanços na visão sobre a natureza da Ciência dos estudantes.

\section{CONSIDERAÇÕES FINAIS}

Os aspectos básicos da História e Filosofia da Ciência não são empregados de forma adequada nos livros didáticos de Química. Todos os livros trazem as biografias dos cientistas, entretanto, são abordadas apenas como uma curiosidade, pois são apresentadas as datas de nascimento e morte, e alguns textos relatam mais sobre suas vidas. Os livros mostram o desenvolvimento da Ciência Química praticamente apenas como uma construção individual dos 
Caderno de Pesquisa em Ensino

de Ciências e Matemática

cientistas. Os aspectos coletivos no desenvolvimento da Ciência Química não são explorados nos livros didáticos.

A discussão e as representações sobre os experimentos científicos empregados para o desenvolvimento dos modelos atômicos são feitas de forma muito superficial também. É necessário estabelecer discussões aprofundadas sobre o papel da experimentação na construção de conhecimento científico, além da relação entre a teoria e a prática.

A contextualização histórica foi observada apenas no LD5, e é uma das tendências apontadas pela Base Nacional Comum Curricular (BRASIL, 2017), e também foi notado que o desenvolvimento da Ciência é apresentado apenas como um crescimento linear, ou seja, não foram discutidas as revoluções científicas. Isso é importante para ser abordado nos livros didáticos, para que os estudantes possuam uma visão mais adequada sobre a natureza da Ciência.

Há alguns pontos relevantes na abordagem HFC que são tocados nos livros de forma muito superficial. É necessário introduzir discussões mais aprofundadas sobre a natureza da Ciência, que permitam que os estudantes superem visões deformadas. Portanto, alguns aspectos são importantes a serem destacados, como explicar o papel da experimentação e dos modelos no desenvolvimento da Ciência, o aspecto coletivo do trabalho dos cientistas e a inserção da ciência em um contexto histórico.

\section{REFERÊNCIAS}

AYIK, Z; COŞTU, B. A Study on Demonstration of the Nature of Science in Science Textbooks: History and Philosophy of Science Perspectives. Jurnal Pendidikan IPA Indonesia, v. 9., n. 3, p. 451-464, 2020.

BRASIL, Ministério da Educação, Fundo Nacional de Desenvolvimento da Educação. Histórico. Disponível em: http://www.fnde.gov.br/programas/programas-do-livro/livrodidatico/historico. Acesso em: 29 de Maio de 2021.

BRASIL, Ministério da Educação. Base Nacional Comum Curricular. 2017. Disponível em: http://portal.mec.gov.br/docman/abril-2018-pdf/85121-bncc-ensino-medio/file. Acesso em: 05 de Fevereiro de 2021.

CACHAPUZ, A., et al. A Necessária Renovação do Ensino de Ciências. Editora Cortez, São Paulo, 2005.

CHALMERS, A. F. O que é Ciência afinal? Editora Brasiliense, 1993.

CISCATO, C. A. M., et al. Química. Vol 1. Editora Moderna São Paulo, 2016. 
COLLINS, S. N. The importance of storytelling in chemical education. Nature Chemistry, v. 13, p. 1-2, 2021.

FONSECA, M. R. M. da Química: ensino médio. 2 ed. São Paulo: Ática, 2016.

GIL PEREZ, D.; et al. Para uma imagem não deformada do trabalho científico. Ciência \& Educação, v. 7, n. 2, p. 125-153, 2001.

HOTTECKE, D. How and What Can We Learn From Replicating Historical Experiments? A Case Study. Science and Education. v. 9, p. 343-362, 2000.

KUHN, T. S. A estrutura das Revoluções Científicas. 12a ed, São Paulo: Perspectiva, 2013.

LISBOA, J. C. F. et al. Ser protagonista. Vol 1. 3 ed. São Paulo: Edições SM, 2016.

MATTHEWS, M. R. Historia, filosofía y enseñanza de las ciencias: la aproximación actual. Enseñanza de las Ciencias, Barcelona, v. 12, n. 2, p. 255-277, 1994.

MORTIMER, E. F.; MACHADO, A. H. Química: Ensino Médio. 3ed São Paulo, Scipione, 2016.

NOVAIS, V. L. D. de.; ANTUNES, M. T. Vivá: Química. Vol.1, Curitiba: Positivo, 2016.

PANTANO, G. et al. Análise da história da ciência no livro didático de química. Scientia Naturalis. v. 3, n. 1, p. 274-287, 2021.

PATTERSON, A., et al. Reading for meaning: The foundational knowledge every teacher of science should have. International Journal of Science Education, v. 3, n. 40, p. 1-17, 2017.

RIBAS H. L.; AIRES J. A. História e Filosofia da Ciência no ensino de química: o que os alunos pensam sobre a colaboração entre os cientistas. In.: Encontro de Educação Química da Bahia. Salvador, 17-20 de Julho de 2012.

ROCHA, J. R. C. da; CAVICHIOLI, A.; Uma Abordagem Alternativa para o Aprendizado dos Conceitos de Átomo, Molécula, Elemento Químico, Substância Simples e Substância Composta nos Ensinos Fundamental e Médio. Química Nova na Escola, n. 21, p. 29-33, 2005.

ROMANELLI, L. I. O Professor e o Conceito Átomo. Química Nova na Escola, n. 3, p. 27 $31,1996$.

SANTOS, J. A. L. et al. A contextualização histórica da evolução em livros didáticos de Ciências. História da Ciência e Ensino - Construindo interfaces, v. 21, p. 87-102, 2020.

SANTOS, W. L. P. dos.; MÓL, G. Química Cidadã. Vol 1, 3 ed., São Paulo; Editora AJS, 2016. 
SANTOS, V. A.; MARTINS, L. A importância do livro didático. Candombá - Revista Virtual, v. 7, n. 1, p. 20-33, 2011.

TERNES, A.; SCHEID, N.; GÜLLICH, R. A História da Ciência em livros didáticos de Ciência utilizados no Ensino Fundamental. In.: Encontro Nacional de Pesquisa em Educação em Ciências. Florianópolis, 8 de novembro de 2009.

VIDAL, P. H.; PORTO, P. A. A História da Ciência nos livros didáticos de Química do PNLEM 2007. Ciência e Educação v. 18, n. 2, p. 291-308, 2012.

Submetido em: 06 de junho de 2021. Aprovado em: 07 de junho de 2021.

Publicado em: 03 de julho de 2021. 